\section{Assessment of endothelial function by flow- mediated dilation of the brachial artery in adolescents with a history of preeclampsia or a normotensive pregnancy}

\section{Avaliação da função endotelial através da dilatação mediada por fluxo da artéria braquial em adolescentes com história de pré-eclâmpsia ou de gestação normotensa}

Joana Adalgisa Furtado Magalhães Andrade 1

Francisco Herlânio Costa Carvalho 2

Rosa Maria Salani Mota 3

Guilherme Augusto Magalhães Andrade 4

Helvécio Neves Feitosa 5

Flávio Lúcio Pontes Ibiapina 6

Francisco das Chagas Medeiros 7

1-7 Departamento de Saúde Materno Infantil. Universidade Federal do Ceará. Rua Prof. Costa Mendes, 1608. $2^{\circ}$ andar. Rodolfo Teófilo. Fortaleza, CE, Brasil. CEP: 60430-140.

E-mail: herlaniocosta@uol.com.br

\begin{abstract}
Objectives: to determine the prevalence of endothelial dysfunction and its association with a history of mild and severe preeclampsia in adolescents.

Methods: a cross-sectional study was carried out at the MEAC-UFC with 103 primiparous adolescents postpartum. The assessment of endothelial function was performed by way of flow-mediated dilatation of the brachial artery. Variables (age, body mass index, gestational age at delivery, systolic and diastolic blood pressure and flow-mediated dilation) were compared between groups. $p<0.05$ was considered to be statistically significant.

Results: twenty-four (23.3\%) patients had preeclampsia (PE): 11 mild and 13 severe. The overall prevalence of endothelial dysfunction was $23.3 \%(21.5 \%$ of patients with normotensive pregnancies and $29.2 \%$ of the PE patients: $18.2 \%$ of those with mild PE and $38.5 \%$ of those with severe PE). The figures were statistically significant for systolic blood pressure, $p=0.007$.

Conclusions: patients with a history of PE have higher systolic blood pressure than patients with a history of normotensive pregnancy, but did not have more endothelial dysfunction.

Key words Pre-eclampsia, Endothelium vascular,
\end{abstract} Adolescent, Ultrasonics, Brachial artery

\section{Resumo}

Objetivos: determinar a prevalência de disfunção endotelial e a associação com o antecedente de préeclâmpsia leve e grave em adolescentes.

Métodos: estudo transversal conduzido na MEAC - UFC com 103 adolescentes primíparas no pósparto. A avaliação da função endotelial foi realizada pela dilatação mediada por fluxo da artéria braquial. As variáveis (idade, índice de massa corporal, idade gestacional no parto, pressão arterial sistólica e diastólica e dilatação mediada por fluxo) foram comparadas entre os grupos. Considerou-se $p<0,05$ significância estatística.

Resultados: vinte e quarto (23,3\%) pacientes tiveram pré-eclâmpsia (PE): 11 PE leve e 13 PE grave. A prevalência geral de disfunção endotelial foi de 23,3\% (21,5\% das pacientes com gestações normotensas e 29,2\% das PE: $18,2 \%$ daquelas com $P E$ leve e $38,5 \%$ daquelas com PE grave). Houve significância estatística para pressão arterial sistólica, $p=0,007$

Conclusões: pacientes com história de PE apresentam pressão sistólica maior que pacientes com antecedente de gestação normotensa, mas não houve mais disfunção endotelial.

Palavras-chave Pré-eclâmpsia, Endotélio vascular, Adolescente, Ultrassom, Artéria braquial 


\section{Introduction}

Preeclampsia (PE) remains one of the main causes of maternal death worldwide. Its incidence varies according to region, although in some countries maternal death rates of up to $40 \%$ have been observed. Of the total female population, primiparous adolescents are at the highest risk of developing preeclampsia. 1

PE is currently described as a disturbance in the balance between pro and anti-angiogenic factors. Roberts et al. ${ }^{2}$ were the first to put forward the hypothesis that the soluble factors that induce endothelial cell dysfunction and are responsible for the onset of clinical symptoms such as hypertension, proteinuria and edemas develop during preeclampsia.

Endothelial dysfunction is defined as an alteration in vascular relaxation due to a decrease in the bioavailability of the relaxing factors derived from the endothelium, particularly nitric oxide. Studies suggest that this dysfunction occurs in response to abnormal placentation, which may lead to placental ischemia and the release of substances that damage the maternal vascular endothelium.1,3

Several methods have been studied to find evidence of this damage, including biochemical techniques and invasive studies. In addition, some researchers have used Doppler ultrasound and have reported significantly increased impedance flows in the brachial artery obtained after a period of forearm ischemia. This flow-mediated dilation (FMD) of the brachial artery is an indicator of endothelial function. This noninvasive method was first described by Celermajer et al., ${ }^{4}$ and is currently recommended by the International Brachial Artery Reactivity Task Force. 5

Numerous studies have employed FMD during pregnancy and indicate that it is significantly lower in pregnant women with PE and thus could be used as a criterion for screening or to provide a prognosis for this pathology. $6-8$

Although it is known that PE symptoms are resolved after delivery, some studies have already investigated FMD during the immediate and/or late postpartum in order to determine whether endothelial dysfunction persists and whether it is responsible for future cardiac episodes in women with a history of PE. Some authors have confirmed the persistence of endothelial dysfunction due to FMD for up to three years after delivery. 1,9-10

Considering that both nulliparity and adolescence are important risk factors for PE, this study highlights the importance of focusing on this popu- lation. The aim of the research is to determine the prevalence of endothelial dysfunction in postpartum adolescents and its relation to a history of preeclampsia and the severity of this pathology.

\section{Methods}

This cross-sectional study was carried out at the Assis Chateaubriand Maternity Teaching Hospital (MEAC) - Universidade Federal do Ceará with primiparous patients aged under 20, who delivered their children in 2007 and 2008. The ultrasound examination (and FMD evaluation) was performed during the postpartum period, which varied from 2 to 11 months.

MEAC is a medical facility providing integral health care for women and includes secondary and tertiary services. It functions as a university hospital and is a center of excellence for the metropolitan region of Fortaleza and other cities in the interior of the Brazilian State of Ceará.

The patients were selected from childbirth records at the medical records service and contacted by phone and/or letter of invitation. The number of deliveries at MEAC were 4,872 (914 adolescents) and 5,310 (926 adolescents) in 2007 and 2008 respectively. The inclusion criteria were primiparous adolescents aged between 10 and 20, with a single pregnancy and a gestational age at labor greater or equal to 24 weeks, who gave birth at the MEAC and had been followed up on the occasion of their return visit. Smokers and patients with other conditions known to be associated with endothelial dysfunction were excluded from the study. The study's aims and methods were explained to the participants, who subsequently signed free and informed consent forms. The legal guardians of patients under 18 signed the form on their behalf. Those who consented to participate and signed the form were then referred to the medical center to undergo FMD. Once FMD had been performed, data on the gestation-index was verified in the patient records and classification into normotensive, mild or severe PE groups was carried out. The three groups were compared according to the following variables: age (completed years), body mass index in the first trimester $\left(\mathrm{kg} / \mathrm{m}^{2}\right)$, time elapsed since childbirth and evaluation (in full months), gestational age at birth (in weeks), postpartum systolic and diastolic blood pressure (in $\mathrm{mmHg}$ ) and FMD (as a percentage). The inclusion criteria were then rechecked in the patients files (Figure 1).

A known diagnosis of diabetes mellitus or other conditions linked to endothelial dysfunction (hyper- 
cholesterolemia, vasculopathy, glomerulopathy, rheumatic diseases and thrombophilia) was an exclusion criterion, although no patient displayed any of these conditions and no patients refused to take the tests.

The ultrasound examinations were performed on LOGIC 5PRO ${ }^{\circ}$ GE equipment, with a high frequency linear transducer (from 6 to $9 \mathrm{MHz}$ ). Following further explanations of the procedure to patients and clarification of any doubts, brachial artery flow-mediated dilation (BAFMD) was evaluated after resting in a quiet, darkened room for a period of 10 minutes. The sample site chosen to obtain the sonogram of the brachial artery was $5 \mathrm{~cm}$ above the bending angle of the elbow.

First, blood pressure and the brachial luminal baseline diameter during diastole in the right arm were measured. Next the arm was compressed for 3 to 5 minutes using a sphygmomanometer cuff with a pressure exceeding the systolic pressure by at least $30 \mathrm{mmHg}$. After releasing compression, the arterial luminal diameter was checked at the following intervals: $30,60,90,120$ and 180 seconds for the diastole in the same place that the baseline measurement was performed. The largest dilation percentagewise was considered for the BAFMD calculation.

All the tests were performed by the same examiner (FHCC), who had no prior knowledge of the patients' gestational history. Each patient was subjected to one test only. Endothelial dysfunction was considered when BAFMD $\leq 10$, with a cutoff point as recommended by Celermajer et al. 4

Figure 1

Criteria for patients' eligibility.

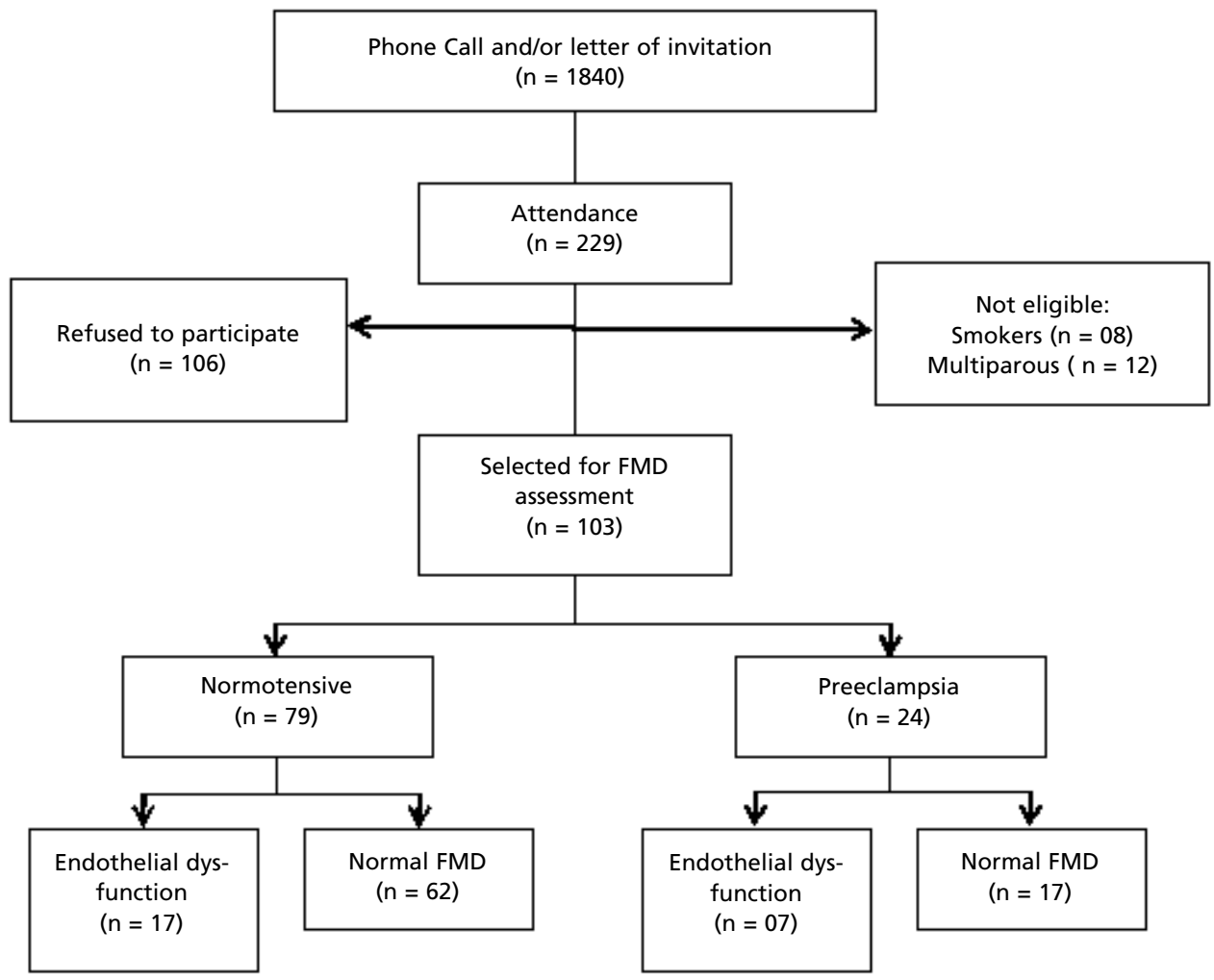

FMD $=$ Flow-mediated dilatation of the brachial artery. 
PE was diagnosed when the blood pressure was $>140 \times 90 \mathrm{mmHg}$ after the $20^{\text {th }}$ week of pregnancy and associated with proteinuria $(1+$ in two measurements or $2+$ in the measurement of an isolated sample or $300 \mathrm{mg} / \mathrm{day}$ in a $24 \mathrm{~h}$ evaluation). The classification of severe preeclampsia was made when at least one of the following criteria was present: (1) $\mathrm{BP}>$ than $160 \times 110 \mathrm{mmHg}$, (2) proteinuria of $3+$ or more in Labstix or 2 grams in a $24 \mathrm{~h}$ sample, (3) clinical signs of imminent eclampsia, (4) oliguria, (5) creatinine greater than $1.2 \mathrm{~g} / \mathrm{dL}$, (6) laboratory findings of HELLP syndrome and (7) seizures and/or coma.

The classification adopted for BMI was: underweight $\left(<18.5 \mathrm{~kg} / \mathrm{m}^{2}\right)$, normal $\left(18.5\right.$ to $\left.24.9 \mathrm{~kg} / \mathrm{m}^{2}\right)$, overweight ( 25 to $29.9 \mathrm{~kg} / \mathrm{m}^{2}$ ), obesity I (30 to 34.9 $\mathrm{kg} / \mathrm{m}^{2}$ ), obesity II ( 35 to $\left.39.9 \mathrm{~kg} / \mathrm{m}^{2}\right)$, obesity III ( $\geq$ $\left.40 \mathrm{~kg} / \mathrm{m}^{2}\right)$. For the purpose of comparison between the groups, BMI was transformed into a categorical variable: low BMI (underweight and normal) or high BMI (overweight and obese).

The study complied with the ethical principles guiding research involving human subjects laid out in the Helsinki Declaration (1964) and amended in Hong Kong (1989), and those of the Brazilian Council of Health (1996), Resolution 196/96. The Ethics Research Committee of the MEAC, Universidade Federal do Ceará, approved the project with no restrictions.

The sample size was calculated using the proportion of endothelial dysfunction in patients with preeclampsia $30 \%, 11$ alpha error of $5 \%$ and beta error $80 \%$ and resulted in an "n" of 21 cases for each group.

Statistical analysis was performed using SPSS ${ }^{\circledR}$ version 13.0 (SPSS Co, Chicago, IL, USA). The association analysis of the contingency tables was performed using Fisher's exact test. For quantitative variables, the normality test was performed using the Shapiro Wilk test and equal variances utilizing the Levene test. The comparison of the mean between the two populations was performed using Student's t test for variables with normal distribution or the Mann-Whitney test when the distribution of variables did not present a normal distribution. Analysis of variance (ANOVA) was used to compare the mean of the three populations for variables with a normal distribution and the Kruskal-Wallis test when the distribution was not normal; $p<0.05$ was considered statistically significant.

\section{Results}

A total of 103 adolescents who met all the inclusion criteria took part in the study. The time between birth and the BAFMD evaluation varied from 2 to 11 months, with an average of $6.6( \pm 2.1)$ months; 13 $(12.6 \%)$ subjects were lactating.

The average age on the day of delivery was 16.2 ( \pm 1.3 ), ranging from 13 to 18 years old; $68.7 \%$ attended prenatal care at the MEAC Adolescents Service.

The BMI was obtained at the beginning of prenatal care in $60(58.3 \%)$ patients. The values obtained ranged from 16.8 to 38.4 , with an average of $23.3( \pm 4.4) \mathrm{Kg} / \mathrm{m}^{2} ; 19(31.7 \%)$ patients were evaluated as overweight or obese and $41(68.3 \%)$ displayed a normal or low BMI.

A total of $24(23.3 \%)$ patients had preeclampsia: 11 had mild PE and 13 severe PE. There were two cases of eclampsia and no cases of HELLP syndrome. The average gestational age was 38.9 ( \pm 1.7) weeks and varied from 31.3 to 41.9 weeks. Sixty-four $(62.1 \%)$ individuals had vaginal deliveries and the other $39(37.9 \%)$ cesarean sections (Csections).

One fetal death occurred in a patient with severe $\mathrm{PE}$ and there were two twin pregnancies. Neonatal data were therefore registered for a total of 104 newborns. The average birth weight was 3,122 grams, ranging from 915 to $4,290 \mathrm{~g}$; seven infants weighed less than $2,500 \mathrm{~g}$. Three infants $(2.9 \%)$ were considered small for their gestational age (SGA) and four $(3.9 \%)$ were large for their gestational age (LGA); the remaining 95 infants had an adequate size for their gestational age (AGA). The first minute Apgar scores ranged from 1 to 9 and from 1 to 10 in the fifth minute; 14 (13.5\%) infants had Apgar scores $<7$ in the first five minutes and $<7(4.8 \%)$ in the fifth minute.

On the day of the FMD evaluation the test subjects rested for 10 minutes before their blood pressure was measured. The findings were as follows: an average SBP of $110.1( \pm 8.1) \mathrm{mmHg}$, varying from 90 to $130 \mathrm{mmHg}$ and an average DBP of $71.2( \pm 7.1) \mathrm{mmHg}$, varying from 60 to $80 \mathrm{mmHg}$.

The average FMD was $16.6 \%( \pm 9.2)$ and the minimum and maximum values measured were $2.7 \%$ and $66.7 \%$ respectively. There were $24(23.3 \%)$ patients with FMD $\leq 10 \%$ ( 8 of them with FMD $<$ $5 \%$ and 16 between 5\% and $10 \%$ ). Measurement of the luminal baseline diameter of the brachial artery before compression obtained an average of 2.9 ( \pm $0.4)$, varying from 1.8 to $3.8 \mathrm{~mm}$. When compression was released after 30 seconds the average was 3.1 ( \pm 0.4 ), varying from 2.0 to $3.9 \mathrm{~mm}$; after 60 seconds, it was $3.2( \pm 0.4)$, varying from 2.3 to $4.4 \mathrm{~mm}$; after 90 seconds, $3.3( \pm 0.4)$, varying from 2.3 to $4.5 \mathrm{~mm}$; 
after 120 seconds, $3.3( \pm 0.4)$, varying from 2.2 to $4.2 \mathrm{~mm}$; and finally, after 180 seconds, the average was $3.2( \pm 0.4)$, varying from 2.1 to $4.2 \mathrm{~mm}$.

The prevalence of endothelial dysfunction assessed by FMD was twenty-three (23.3\%). If this rate is taken as $100 \%, 21.5 \%$ of cases were previous normotensive pregnancies; $29.2 \%$ of the individuals had a history of PE; $18.2 \%$ of the patients had mild PE; and 38.5\% suffered from severe PE. The cases were initially organized and compared in three groups: no history of PE ( $\mathrm{n}=79)$, mild PE $(\mathrm{n}=11)$, and severe PE $(n=13)$ taking the following factors into account: age, time between delivery and FMD evaluation, systolic and diastolic blood pressure, BMI (early pre-natal) and gestational age at delivery and evaluation by FMD, including the luminal artery diameters at all times of evaluation. ANOVA (analysis of variance) was used to compare the groups where the variables had a normal distribution and the Kruskal-Wallis test was applied to variables whose distribution was not normal. The only significant difference was for SBP, $p=0.007$ (Tables 1 and 2). Group to group comparisons revealed differences between the SBP of the normotensive pregnancies and mild PE groups $(p=0.006)$, with no difference for severe $\operatorname{PE}(p=0.110)$.

Table 1

Comparison of patients with or without a history of preeclampsia and classification (mild or severe) by age, BMI, interval between childbirth and evaluation, blood pressure and gestational age at birth.

\begin{tabular}{|c|c|c|c|c|}
\hline \multirow{3}{*}{ Variables } & \multicolumn{3}{|c|}{ Prior diagnosis } & \multirow{3}{*}{$p$} \\
\hline & Without PE & Mild PE & Severe PE & \\
\hline & $\bar{X} \pm S D$ & $\bar{X} \pm S D$ & $\bar{X} \pm S D$ & \\
\hline Age (years) & $16.3 \pm 1.3$ & $15.9 \pm 1.3$ & $15.8 \pm 1.4$ & $0.327 *$ \\
\hline BMI $\left(\mathrm{kg} / \mathrm{m}^{2}\right)$ & $22.76 \pm 4.39$ & $26.14 \pm 4.95$ & $24.35 \pm 3.08$ & $0.090 *$ \\
\hline Interval (months) & $6.7 \pm 2.1$ & $6.1 \pm 2.4$ & $6.3 \pm 1.8$ & $0.747 *$ \\
\hline Systolic BP (mmHg) & $109.1 \pm 7.7$ & $117.3 \pm 7.9$ & $110.0 \pm 8.2$ & $0.007 *$ \\
\hline Diastolic BP (mmHg) & $70.6 \pm 7.3$ & $73.6 \pm 6.7$ & $73.1 \pm 6.3$ & $0.252^{*}$ \\
\hline GA at birth (weeks) & $39.0 \pm 1.6$ & $39.3 \pm 2.1$ & $38.3 \pm 2.1$ & $0.164 * *$ \\
\hline
\end{tabular}

* ANOVA; ** Kruskal-Wallis test; $\mathrm{PE}=$ preeclampsia; $\mathrm{SD}=$ standard deviation; $\mathrm{BMI}=$ body mass index; interval= interval between delivery and assessment; $\mathrm{BP}=$ blood pressure; $\mathrm{GA}=$ gestational age.

Table 2

Comparison of FMD among patients with or without preeclampsia (mild or severe).

\begin{tabular}{|c|c|c|c|c|}
\hline \multirow{3}{*}{ Variables } & \multicolumn{3}{|c|}{ Prior diagnosis } & \multirow{3}{*}{$p$} \\
\hline & Without PE & Mild PE & Severe PE & \\
\hline & $\bar{X} \pm S D$ & $\bar{X} \pm S D$ & $\bar{X} \pm S D$ & \\
\hline Baseline brachial art (mm) & $2.9 \pm 0.4$ & $2.8 \pm 0.3$ & $2.9 \pm 0.5$ & 0.747 \\
\hline Brachial art $30 \mathrm{~s}(\mathrm{~mm})$ & $3.1 \pm 0.4$ & $2.9 \pm 0.4$ & $3.0 \pm 0.4$ & 0.502 \\
\hline Brachial art $60 \mathrm{~s}(\mathrm{~mm})$ & $3.2 \pm 0.4$ & $3.2 \pm 0.3$ & $3.2 \pm 0.4$ & 0.863 \\
\hline Brachial art $90 \mathrm{~s}(\mathrm{~mm})$ & $3.3 \pm 0.4$ & $3.2 \pm 0.3$ & $3.3 \pm 0.5$ & 0.726 \\
\hline Brachial art $120 \mathrm{~s}(\mathrm{~mm})$ & $3.3 \pm 0.4$ & $3.2 \pm 0.3$ & $3.3 \pm 0.5$ & 0.551 \\
\hline Brachial art $180 \mathrm{~s}(\mathrm{~mm})$ & $3.2 \pm 0.4$ & $3.1 \pm 0.3$ & $3.2 \pm 0.5$ & 0.767 \\
\hline FMD (\%) & $16.6 \pm 7.9$ & $16.5 \pm 5.9$ & $16.9 \pm 12.5$ & 0.999 \\
\hline
\end{tabular}

* ANOVA; $\mathrm{PE}=$ preeclampsia; $\mathrm{SD}=$ standard deviation; Art= Artery; FMD= flow-mediated dilatation. 
The comparison was subsequently limited to two groups: those with a history of $\mathrm{PE}(\mathrm{n}=24)$ and subjects who had a normotensive pregnancy $(n=79)$ using Student's t test for variables with a normal distribution and the Mann-Whitney test for variables whose distribution was not normal. Statistically significant differences between the groups were found for systolic blood pressure $(p=0.008)$ and the
BMI measured during early prenatal care $(p=0.031)$.

A line graph was plotted to show the comparison between the evaluations of the diameter $(\mathrm{mm}$, average \pm standard deviation) of the brachial artery before and after compression among patients with a history of PE or a history of normotensive pregnancy (Student's t test ranged from 0.119 to 0.974 ) (Figure 2).

\section{Figure 2}

Development of dilation of baseline diameter of brachial artery after releasing compression in primiparous adolescents with a history of PE or normotensive pregnancy.

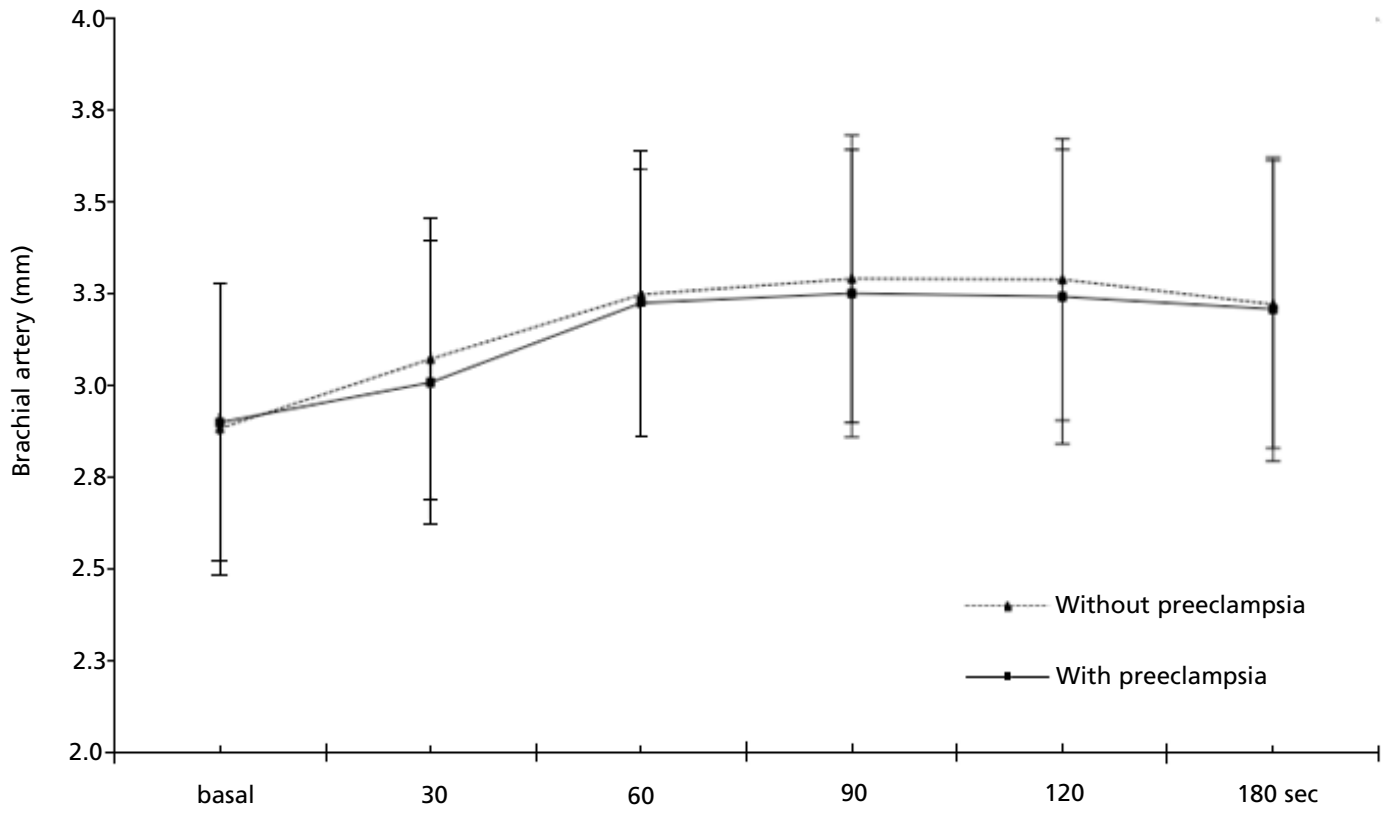

*Brachial artery, $\mathrm{mm}$ (average \pm standard deviation). Student's $\mathrm{t}$ test between without and with preeclampsia ranged from 0.119 to 0.974 .

\section{Discussion}

The relationship between $\mathrm{PE}$ and endothelial dysfunction has been well established; the fact that ultrasound is a non-invasive technique and the test is easily reproduced explains why there are so many studies attempting to show the efficacy of FMD as a predictor of or factor correlated with PE.2,9

$\mathrm{PE}$ is a syndrome whose symptoms regress directly after delivery. In an attempt to establish whether endothelial lesions persist in the long term, and whether they are also associated with inflamma- tory and metabolic factors after pregnancy, several studies carried out during puerperium have indicated that, in women with PE and eclampsia, the damage persists until three years postpartum, more than among women with hypertension or previous normotensive pregnancies. ${ }^{1,9-10} \mathrm{Kuscu}$ et al. ${ }^{11} \mathrm{did}$ not identify the persistence of endothelial dysfunction during the postpartum period. The changes in FMD observed in patients with preeclampsia during pregnancy and one week after childbirth had disappeared by the sixth week postpartum.

Adolescents are one of the main high risk groups 
for PE and this is especially the case in Brazil where adolescents account for approximately $25 \%$ of all childbirths, contributing to the high rates of maternal mortality. 12

It is thus not clear whether the relationship between endothelial dysfunction and preeclampsia in adolescents is as clear as it is in other population groups or whether the persistence of endothelial dysfunction occurs in adolescents who have developed preeclampsia. Both of these scenarios are extremely important. The purpose of the present clinical study was to establish or confirm the importance of endothelial dysfunction as a risk factor for $\mathrm{PE}$ in adolescents and to identify whether this abnormality persists postpartum.

The present study only covered primiparous adolescents, more than $70 \%$ of whom were aged between 16 and 18 years, a period considered to be late adolescence; and on average the FMD evaluation took place six months postpartum. A total of twenty-four $(23.3 \%)$ patients had a history of PE and twenty-four $(23.3 \%)$ presented a FMD $\leq 10 \%$.

There is no consensus in the literature regarding the cutoff point when dilation after the deflation of the cuff should be considered to indicate a dysfunctional endothelium. According to Meireles et al.,13 an FMD below $10 \%$ for men and $15 \%$ for women indicates high sensitivity to coronary artery disease. Gomez-Cerezo et al.14 consider that impaired endothelial function occurs when the FMD is $<5 \%$ 60 seconds after an occlusion of 4 minutes. These authors reported a negative predictive value of $100 \%$ for PE. Faulex et al. 15 reported that healthy arteries have an FMD of between 5 and $15 \%$. In the present study, an FMD $\leq 10 \%$ was considered to indicate endothelial dysfunction and an FMD $>10 \%$ normal endothelial function, in accordance with the criteria proposed by Celermajer et al. ${ }^{4}$ The present study opted to use the criteria and cutoff proposed by Celermajer et al. ${ }^{4}$ as it is the most long-standing description and is cited in the literature on noninvasive assessment of endothelial function and therefore provides for better comparison with other authors who evaluated postpartum women using the same criteria. $1,10,11$

FMD is an indicator of endothelial function and can be affected by chronic conditions such as obesity, diabetes, hypercholesterolemia, smoking and hypertension, and also by factors such as sleep deprivation, stress, hormonal changes, physical exercise, the menstrual cycle and diet. The reliability of the FMD results may be subject to variations in the procedure, such as the site of cuff placement, the occlusion time, the resolution of the transducer, the experience of the health professional carrying out the ultrasound examination and intra-individual variation. 13 To reduce some of these variations all the evaluations were performed by a single professional who followed a standardized collection protocol.

There is no consensus regarding the best time for data collection for the percentage dilation and consequently the FMD. Some studies have carried out measurements one minute after cuff deflation; others at 30 and 90 seconds, and others at even greater intervals. ${ }^{13}$ The present study's collection protocol included measurements at 30,60, 90, 120 and 180 seconds after deflation. The largest expansion observed was used to calculate the FMD. The maximum dilation time after reactive hyperemia was found at 90 seconds. Celemajer's technique was used in this research because it is the most commonly used method in the literature, ensuring that the results are consistent with those of previous studies. Initially the patients were divided into three groups (normotensive pregnancy, mild PE and severe PE). Although endothelial dysfunction was more frequent in patients with PE, particularly in the severe group, no statistical difference was found between these groups regarding the presence of endothelial dysfunction and the luminal diameter of the brachial artery at any point in the evaluation.

The values for the luminal artery are similar to those found by Yoshida et al. 6 and Yamamoto et al. 8 However, the FMD values are greater than those found during pregnancy and also higher than those found in late postpartum by Chambers et al. 9 However, none of these studies was conducted exclusively with adolescents and there is no data available for comparison with other studies in such young patients. Dilation of the brachial artery and consequently the FMD may be greater in younger patients.

Another study with postpartum patients was carried out by Kuscu et al. ${ }^{11}$ covering 26 individuals: 15 with PE and 11 normotensive patients of the same gestational age. The test was repeated at one and six weeks postpartum using Celermajer et al.4's technique. All the patients with preeclampsia had a FMD below $10 \%$. In the present study, however, the levels of FMD returned to normal in the sixth week postpartum, indicating that the endothelial function went back to normal at the end of puerperium. Patients thus recovered the ability to dilate their arteries after hypoxia caused by sheer stress.

In the present study, at six months postpartum, on average, FMD was $\leq 10 \%$ in $29.2 \%$ of patients with a history of $\mathrm{PE}$, and in normotensive pregnancies $21.5 \%$ were found to involve abnormal FMD. 
These patients had not been evaluated during pregnancy. These groups only differed in terms of systolic blood pressure evaluated at the point of confirmation of FMD. The BMI (measured at the beginning of the pregnancy) also showed a statistically significant difference when the two groups were compared (normotensive pregnancy versus $\mathrm{PE}$ ). The blood pressure measured during prenatal care was not statistically significant when comparing the groups in the present study.

It can be assumed that adolescents with BMI and/or high baseline SBP have a greater risk of developing PE. Similar findings have been described for over ten years by Sibai et al.,16 who evaluated 4,589 nulliparous pregnant women in five different medical centers $(630$ of whom were $<17$ years of age). A total of $7.6 \%$ developed PE $(7.3 \%$ in those under 17 years of age and $7.6 \%$ in those aged between 17 and 24 years). The following risk factors were identified: BMI, high SBP and DBP. These authors reported that an increased BMI, especially in the second trimester is a strong predictor of PE with increasing incidence $(12.6 \%$ among women with BMI $\left.>34 \mathrm{~kg} / \mathrm{m}^{2}\right)$. This is consistent with other studies that report an increased incidence of PE in obese nulliparous women. At the time, Sibai et al. 16 suggested that these risk factors may contribute to understanding of the pathophysiological characteristics of this syndrome (PE). The prevalence of PE of $23.3 \%$ found in the present study was well above that reported by the aforementioned authors. This high prevalence may be explained by the fact that the MEAC is a center of excellence for high-risk pregnancies.

Takata et al.7 also studied endothelial dysfunction in various levels of PE using measurement of FMD in the brachial artery and Doppler measurements in the uterine and ophthalmic arteries, concluding that FMD was significantly lower in pregnant women with PE than in non-pregnant women. Data obtained by Takata and colleagues also suggests that FMD evaluation of the brachial artery helps to identify the level and severity of PE and is useful in understanding the circulatory condition of women with PE.

Since the present study was cross-sectional, some data were absent or may have been inaccurate, such as the classification of PE as mild or severe recorded in the charts. However, all medical records were reviewed before considering the classification registered on discharge and the two sets of data were in full concordance. Despite a mean time of six months for follow up after delivery, there was only $12.4 \%$ response to mailings/phone calls. There was also large proportion of refusals $(46.3 \%)$.

The findings of the present study have not established a direct relation between FMD and PE in adolescents specifically. This raises the question of whether this population has a unique pathophysiological mechanism compared to other populations or whether the group of participants used in the research was too small and the data consequently not truly representative of the adolescent population.

There has been no similar trial, focusing specifically on adolescents. The present study found no difference between the group with PE (even after separating mild and severe $\mathrm{PE}$ ) raising the possibility that the pathophysiology of PE in adolescents may be different from that of the same disorder in older women. This may partially explain the lack of efficacy of prophylaxis for PE with acetyl salicylic acid (ASA) in this specific group of high-risk patients (adolescents). Sibai17 and Subtil et al.18 showed a lack of benefit in the group of nulliparous women, including teens.

Another explanation involves the selected population (who responded to calls and agreed to participate in the research). The pre-eclampsia groups mostly had late PE, as the mean gestational age was 38-39 weeks. There were few cases of early PE, precluding statistical comparison with late PE. Early PE seems to have a pathophysiological mechanism different from that of late PE, with differences in clinical presentation and complications. Late PE has higher BMI and cardiac output and decreased total vascular resistance when compared to early PE. In fact, these two conditions are currently regarded as being distinct phenomena. The findings support the hypothesis of significant hemodynamic differences between the two. The origins of PE are also probably different: early PE seems to be more linked to placental factors and deficient trophoblastic invasion and late PE to maternal factors, such as high BMI. Our data showed the difference in BMI between groups. ${ }^{19}$ Valensise et al. ${ }^{19}$ emphasized the possibility that different strategies may be needed to prevent PE.

A recent meta-analysis showed that ASA may prevent early, but not late PE. 20 This meta-analysis did not examine adolescents specifically or separately. One hypothesis is that patients with early $\mathrm{PE}$ have more endothelial dysfunction during pregnancy and in the long term. There is no information on the efficacy of ASA in patients with endothelial dysfunction in pregnancy.

The findings of the present study suggest that assessment of endothelial function in selecting patients who will respond to aspirin may contribute 
to future strategies for prevention of PE. In this regard, a randomized, multicenter study should be considered. Future studies required in this field include prospective (cohort) follow-ups of adolescents with abnormal FMD to confirm the association between endothelial dysfunction and abnormalities in the Doppler reading of the uterine artery. Much research clearly still needs to be carried out in this field.

The prevalence of endothelial dysfunction evalu-

\section{References}

1. Agatisa PK, Ness RB, Roberts JM, Costantino JP, Kuller LH, Mclaughlin MK. Impairment of endothelial function in women with a history of preeclampsia: an indicator of cardiovascular risk. Am J Physiol, Heart Circ Physiol. 2004; 286: 1389-93

2. Roberts JM, Taylor RN, Musci TJ, Rodgers GM, Hubel CA, Mclaughlin MK. Preeclampsia: an endothelial cell disorder. Am J Obstet Gynecol. 1989; 161:1200-4.

3. Muy-Rivera M, Vadachkoria S, Woelk GB, Qiu C, Mahomed K, Williams MA. Maternal plasma VEGF, sVEGF-R1, and PlGF concentrations in preeclamptic and normotensive pregnant Zimbabwean women. Physiol Res. 2005; 54: 611-22.

4. Celermajer DS, Sorensen KE, Gooch VM, Spiegelhalter DJ, Miller OI, Sullivan I.D, Lloyd JK, Deanfield JE. Noninvasive detection of endothelial dysfunction in children and adults at risk of atherosclerosis. Lancet. 1992; 340: 1111-5.

5. Corretti MC, Anderson TJ, Benjamin EJ, Celermajer D, Charbonneau F, Creager MA, Deanfield J, Drexler H, Gerhard-Herman M, Herrington D, Vallance P, Vita J, Vogel R, International Brachial Artery Reactivity Task Force. Guidelines for the Ultrasound Assessment of EndothelialDependent Flow-Mediated Vasodilatation of the Brachial Artery. A Report of International Brachial Artery Reactivity Task Force. J Am Coll Cardiol. 2002; 39: 257-65.

6. Yoshida A, Nakao S, Kobayashi H, Kobayashi M. Noninvasive assessment of flow-mediated vasodilatation with 30-MHz transducer in pregnant women. Hypertension. 1998; 31: 1200-1.

7. Takata M,Nakatsuka M, Kudo T. Differential blood flow in uterine, ophthalmic, and brachial arteries of preeclamptic women. Obstet Gynecol. 2002; 100: 931-9.

8. Yamamoto T, Suzuky Y, Kojima K, Suzumori K. Reduced flow-mediated vasodilatation is not due to a decrease in production of nitric oxide in preeclampsia. Am J Obstet Gynecol. 2005; 192: 558-63.

9. Chambers JC, Fusi L, Malik IS, Haskard DO, De Swiet M Kooner JS. Association of maternal endothelial dysfunction with preeclampsia. JAMA. 2001; 285: 1607-12. ated by FMD in primiparous adolescents was $23.3 \%$, (21.5\% in previous normotensive pregnancies and $29.2 \%$ in those with a history of PE: $18.2 \%$ in patients with mild $\mathrm{PE}$ and $38.5 \%$ in those with severe PE).

Patients with a history of PE displayed a systolic blood pressure higher than those with normotensive pregnancies. No statistically significant differences were found between the groups regarding the presence of endothelial dysfunction evaluated by FMD.

10. Hamad RR, Eriksson MJ, Silveira A, Hamsten A, Bremme $\mathrm{K}$. Decreased flow-mediated dilation is present 1 year after a pre-eclamptic pregnancy. J Hypertens. 2007; 25 (11): 2301-7.

11. Kuscu NK, Kurhan Z, Yildirim Y, Tavli T, Koyuncu F. Detection of endothelial dysfunction in preeclamptic patients by using color Doppler sonography. Arch Gynecol Obstet. 2003; 268 (2): 113-6.

12. Vega CEP, Kahhale S, Zugaib M. Maternal mortality due to arterial hypertension in São Paulo City (1995-1999). Clinics. 2007; 62 (6): 679-84.

13. Meirelles CM, Leite SP, Montenegro CA, Gomes PS. Reliability of brachial artery flow-mediated dilatation measurement using ultrasound. Arq Bras Cardiol. 2007; 89 (3): $160-83$.

14. Gómez-Cerezo J, Blanco JJR, García IS, Anaya PM, Raya PG, Vásquez-Muñoz E, Hernandez FJB. Noninvasive Study of Endothelial Function in White Coat. Hypertension. 2002; 40 (3): 304-9.

15. Faulex MD, Wright AT, Heit BD. Detection of endothelial dysfunction with brachial artery ultrasound scanning. Am Heart J. 2003; 145 (6): 943-51.

16. Sibai BM, Ewell M, Levine RJ, Klebanoff MA, Esterlitz J, Catalano PM, Goldenberg RL, Joffe G. Risk factors associated with preeclampsia in healthy nuliparous women. The Calcium for Preeclampsia Prevention (CPEP) study group. Am J Obstet Gynecol. 1997; 177 (5): 1003-10.

17. Sibai BM. Prevention of preeclampsia: a big disappointment. Am J Obstet Gynecol. 1998; 179 (5): 1275-8.

18. Subtil D, Goeusse P, Puech F, Lequien P, Biausque S, Breart G, Uzan S, Marquis P, Parmentier D, Churlet A, Essai Régional Aspirin Mère-Enfant (ERASME) Collaborative Group. Aspirin $(100 \mathrm{mg})$ used for prevention of preeclampsia in nulliparous women: the Essai Régional Aspirine Mère-Enfant study (Part 1). BJOG. 2003; 110 (5): 475-84. 
19. Valensise H, Vasapollo B, Gagliardi G, Novelli GP. Early and late preeclampsia: two different maternal hemodynamic states in the latent phase of the disease. Hypertension. 2008; 52 (5): $873-80$

Recebido em 16 de abril de 2013

Versão final apresentada em 22 novembro de 2013

Aprovado em 30 de dezembro de 2013
20. Roberge S, Villa P, Nicolaides K, Giguére Y, Vainio M, Bakthi A, Ebrashy A, Bujold E. Early administration of low-dose aspirin for the prevention of preterm and term preeclampsia: a systematic review and meta-analysis. Fetal Diagn Ther. 2012; 31 (3): 141-6. 